\title{
Cost estimation and consumer acceptance studies of herbal burfi
}

\author{
Writdhama Prasad, Kaushik Khamrui, Gunvantsinh Rathod and Hari Ram Gupta
}

Received: 29 October 2018 / Accepted: 20 January 2019 / Published online: 18 April 2019

(C) Indian Dairy Association (India) 2019

\begin{abstract}
Traditional Indian dairy product has huge liking throughout the length and breadth of our country as well as abroad in the Indian diaspora. However, increasing health consciousness among the consumers has resulted into shift in their demand to functional foods. Many reports have highlighted the scope of further enhancing traditional dairy foods market by increasing their functionality, however very limited literature is available regarding their market prospects. The present study was conducted to estimate the production cost of herbal burfi, rich in anti-oxidative activity, in comparison to control burfi and also the market potential of the same. Herbal essential oil incorporation resulted into increase in INR 6/- of the raw material cost and thus the production cost of herbal burfi was INR 6/$(2.75 \%)$ was higher than that from control burfi. Consumer survey of the developed product revealed that $22.73 \%$ of the respondents rated the product 'excellent' and $92.86 \%$ of 154 respondents were ready to purchase the product, when available in market even at slightly higher price.
\end{abstract}

Keywords: Burfi, Consumer acceptance, Production cost

Writdhama Prasad $(\square)$

Dairy Technology Division, ICAR-National Dairy Research Institute,

Karnal-132 001 (Haryana), India

E-mail: writdhama_3993@rediffmail.com,

Ph: 0184-2259247; Fax: 0184-2250042

Kaushik Khamrui, Gunvantsinh Rathod and Hari Ram Gupta Dairy Technology Division, ICAR-National Dairy Research Institute, Karnal-132 001 (Haryana), India
Traditional Indian dairy products have a huge demand, while their domestic markets are well established, global market appears as silver lining for large Indian diaspora living abroad. However, in order to survive and to cope up with the ever rising functional food market, improvement in functionality and novelty in traditional dairy product is immensely required. Burfi, a popular $k h o a$ based sweetmeat, rich in essential nutrients (Palit and Pal, 2005; Rathod and Khamrui, 2015). It is needless to say that herbs such as turmeric, ginger, cardamom possess superior antioxidant properties. Along with that they have anti-mycotic, anticarcogenic, anti-diabetic, anti-bacterial, anti-viral, hypotensive, hypocholesteremic properties (Hussain et al., 2015). Hence, these herb will not only provide better shelf-life with antioxidant properties but also addition benefits. Prasad et al (2017a,b) reported increase in anti-oxidant activity of burfi upon incorporation of herbs into it. Incorporation of ginger into rye bread increased its shelf life by delaying lipid oxidation (Zieliński, et al., 2012). Buch et al., (2014) reported increased keeping quality of paneer upon incorporation of turmeric into it. Studies regarding preparation of herbal burfi, its anti-oxidant properties and shelflife studies were reported earlier.

This document focus on production cost estimation and consumer acceptance of herbal burfi. Market acceptance and sustainability of newly develop product depends on it cost and consumer acceptance studies. Earlier, some workers have done similar studies for dietetic burfi (Prabha, 2006), Dietetic peda (Rathod, 2013) which was taken as base studies for calculation of cost and consumer survey.

Preparation of herbal burfi for consumer survey: Burfi was prepared by atmospheric desiccation of standardized milk using the method of Prasad et al (2017c).

Cost of production of herbal burfi was calculated as per the method followed by Prabha (2006) considering the prevailing price of all ingredients being used in the product manufacturing.

154 respondents were randomly selected from among residents, staff and students of National Dairy Research Institute (Karnal) fairly representing a cross-section of the social 33 strata. Each 
Fig.1 Consumer response to the developed herbal burfi

\section{CONSUMERS' RATING}

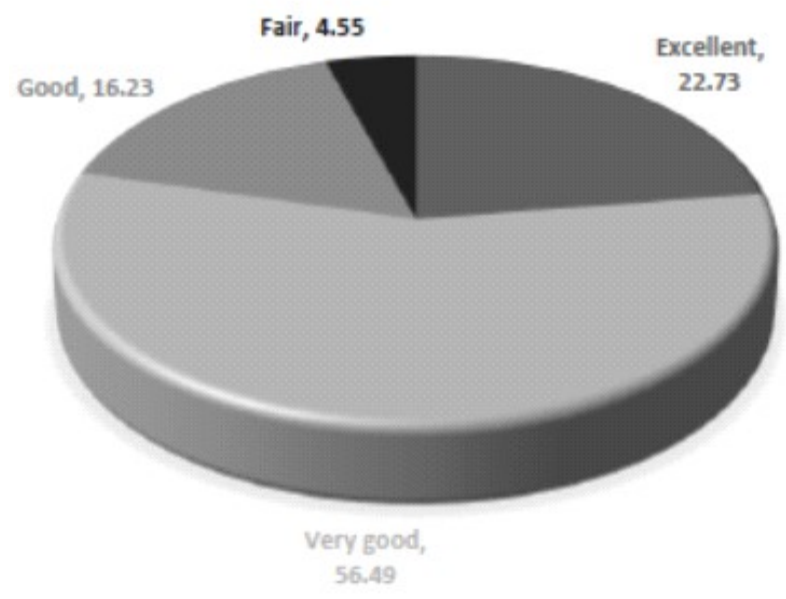

\section{Consumer rating of the developed herbal burfi}

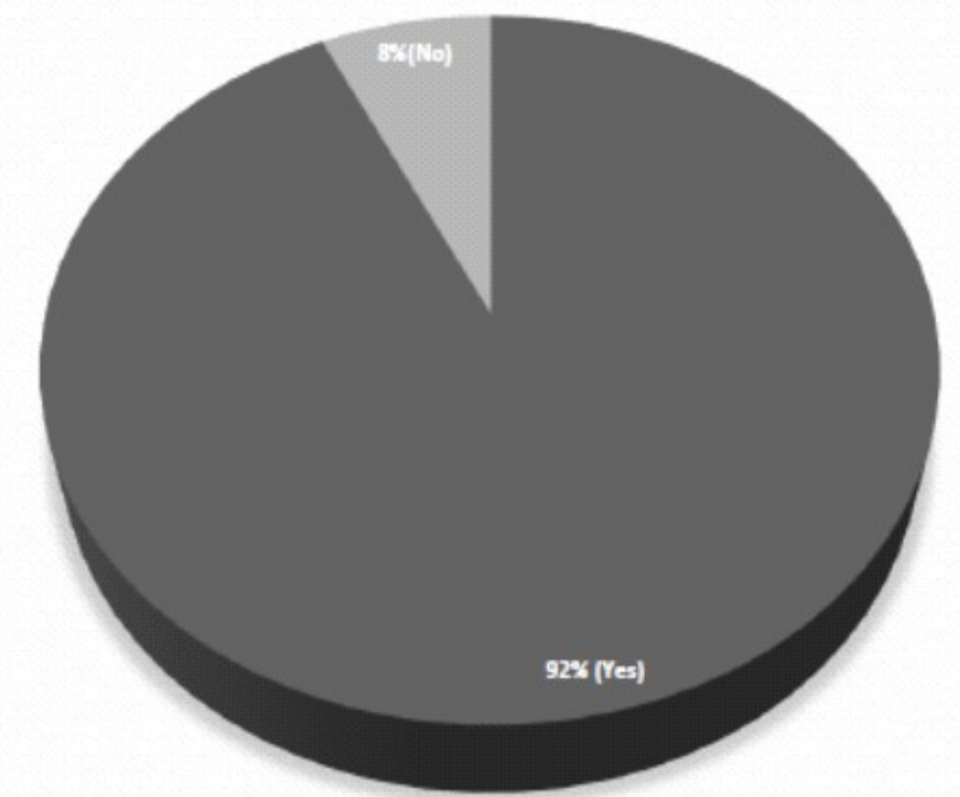

Consumer's willingness to buy the herbal burfi knowing that it contains herbal extract and priced slightly higher than conventionally available burfi

Table 1 Estimated cost of raw materials and services required for production of $1 \mathrm{~kg}$ each of control and herbal burfi

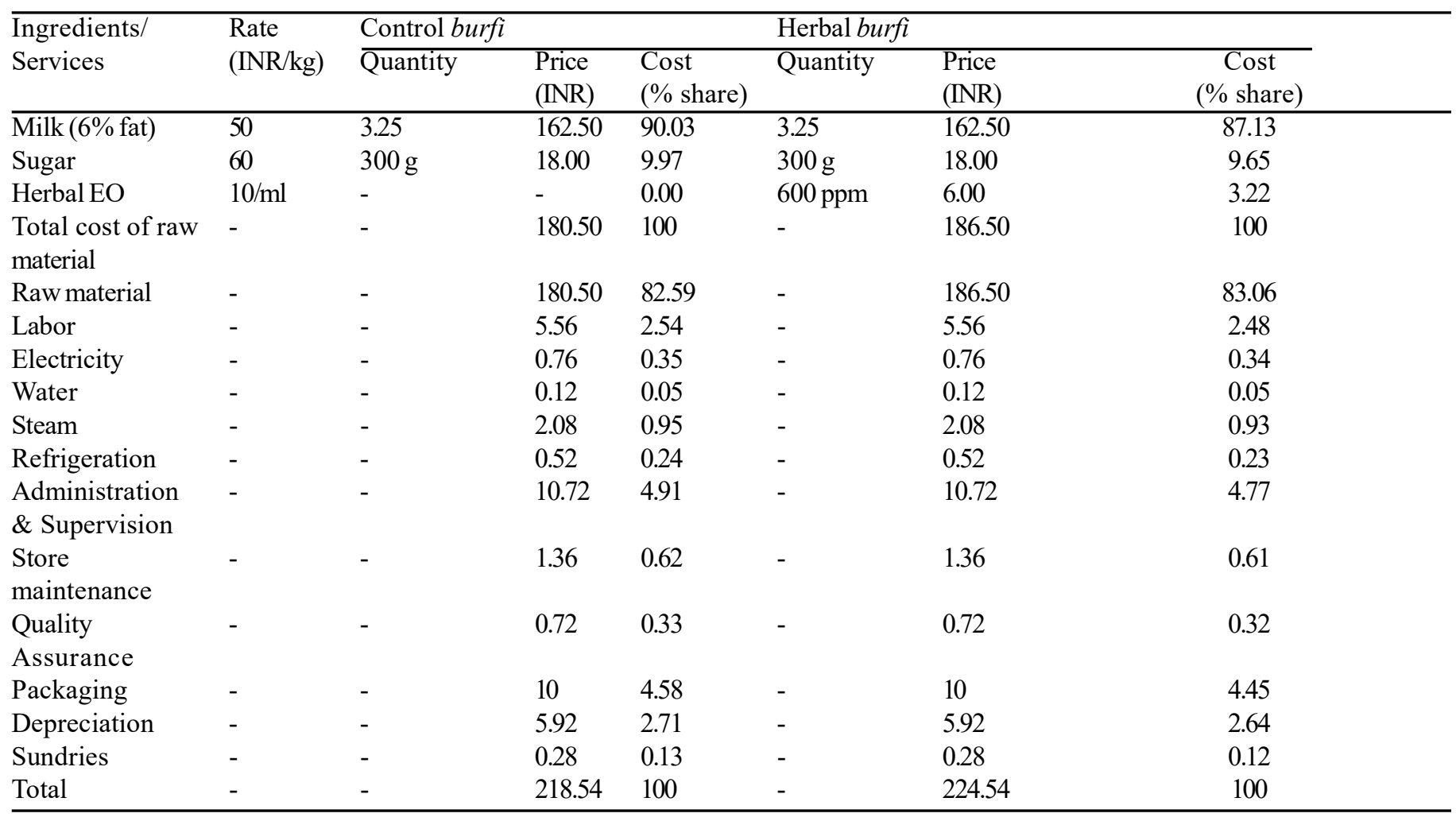


respondent was given a $15-50$ gms (1-5 pieces) of herbal burfi and a questionnaire and their responses were recorded.

Cost is of prime consideration for any product. With increasing awareness, consumer are more calculative towards what they spent and what they get. So, still when it comes to a buying decision, cost has huge weightage. Consumer compare different brands for price as well as quality. Either side of coin, cost also matters a lot for the manufacturer. Manufacturing cost is one of the important considerations for establishing a remunerative project. In present studies, cost is calculate based on commercial set up. Here assumption was taken that herbal burfi was manufactured in the Experimental Dairy of the Institute, considering production of 4906 packages (of $1 \mathrm{~kg}$ each) per day. As the prime objective of this exercise was to estimate the increase in cost of herbal burfi with respect to control burfi. Data provided by Prabha (2006) for various operational costs were used based upon percentage cost of raw materials. Raw material cost (Table 1) was calculated considering the prevailing prices of ingredients in the local market.

Total cost of raw material for herbal burfi was found out to be INR 186.50 which was INR $6(3 \%)$ higher than that from the raw material cost for control or control burfi (INR 180.50). Addition of essential oil to burfi did not increase the cost of raw materials to a large extent. Further, sugar comprised 9.97 and $9.65 \%$ of the total cost of raw materials in preparation of control and herbal burfi.

Percent break-up of major manufacturing cost items are presented in Table 1. The total cost of production was estimated to be INR 224.54 for herbal burfi and INR 218.54 for control burfi. It could be inferred that increase in cost of herbal burfi (2.75\%) as compared to that of control burfi is due to the addition of herbal essential oil into it. Comparing $2.75 \%$ increase in cost with $33 \%$ increase in shelf life (from 6 to 8 days) of burfi with incorporation of herbal essential oil at $37^{\circ} \mathrm{C}$, it could be concluded that herbal burfi is more profitable as compared to control burfi owing to its higher shelf life. Further, tag of "herbal product" seems to fetch more customers as compared to "control product" with a difference of only $2.75 \%$ in their costs.

Customers are thought to be the real judges of any product. Consumer survey of developed herbal burfi was done with an intention to judge the probability of products success, when launched in the market. 154 respondents, representing a range of income groups and age groups, were provided with herbal burfi. Respondents comprised $53.25 \%$ males and $46.75 \%$ females. The consumer's preference for conventionally available burf $i$ is presented in Table 1. It was found that around $65 \%$ of the respondents consume burfi at least once in a week. But all the consumers of the survey had the experience of consuming burfi earlier (Table 1).

Consumers' rating of the newly developed herbal burfi is pre- sented in Fig 1. It can be seen that consumers liked the product well, with $22.73 \%$ of respondents rated it "excellent" and $56.49 \%$ as "very good" (Fig 1). It can be seen that the new product has high probability of success in the market as $92.86 \%$ respondents were ready to purchase the product even when it was priced slightly higher than those available in the market (Fig 1).

\section{Conclusions}

Considering current scenario, people are more inclined towards new herbal products having health benefits. Herbal burfi has an additional health benefits and extended shelf-life than conventional one. Herbal burfi can be highlighted under the class of health beneficial foods with marginal increase cost. Consumer are willing to buy herbal burfi with slightly higher price as they are getting additional benefits with small elevated price. From the manufacturer point of view, herbal burfi will be profitable as it cost effective as well good consumer acceptance.

\section{References}

Buch S, Pinto S, Aparnathi KD (2014) Evaluation of efficacy of turmeric as a preservative in paneer. J Food Sci Tech 51(11), 3226-3234

Hussain SA, Panjagari NR, Singh RRB, Patil GR (2015) Potential herbs and herbal nutraceuticals: food applications and their interactions with food components. Cric Rev Food Sci Nutri 55(1) 94-122

Palit C, Pal D (2005) Studies on mechanized production and shelf life extension of burfi. Indian J Dairy Sci 58(1):12-16

Prabha S (2006) Development of technology for the manufacture of dietetic burfi. Ph.D, thesis. National Dairy Research Institute (Deemed University), Karnal

Prasad W, Khamrui K, Snadhya S (2017c) Effect of packaging materials and essential oils on the storage stability of burfi, a dairy dessert. J Pack Tech Res. DOI: 10.1007/s41783-017-0018-x.

Prasad W, Khamrui K., Mandal S, Badola R (2017a) Anti-oxidative, physicochemical and sensory attributes of burfi affected by incorporation of different herbs and its comparison with synthetic anti-oxidant (BHA). J Food Sci Tech 54(12) 3802-3809

Prasad W, Khamrui K, Mandal S, Badola R, Sandhya S, Gupta HR (2018b) Effect of incorporation of herbal essential oil on anti-oxidative, instrumental color and sensorial attributes of burfi. Indian J Dairy Sci 71(1):70-75

Rathod GI (2013) Development of technology for dietetic peda. Ph.D, thesis. National Dairy Research Institute (Deemed University), Karnal

Rathod GI, Khamrui K (2015) Instrumental texture profile of reduced calorie Peda as a function of ingredients using response surface methodology. Int J Dairy Tech 8(4) 543-549

Zieliński H, del Castillo MD, Przygodzka M, Ciesarova Z, Kukurova K, Zielińska D (2012) Changes in chemical composition and antioxidative properties of rye ginger cakes during their shelf-life. Food chem 135(4) 2965-2973 